\title{
1 Factors Related to the Academic Performance of 2 Students in the Statistics Course in Psychology
}

\author{
3 JOAN GUÀRDIA*, MONTSERRAT FREIXA, MARIBEL PERÓ, \\ 4 JAUME TURBANY, ANTONIO COSCULLUELA, MAITE BARRIOS \\ 5 and XAVIER RIFÀ \\ 6 Dept. de Metodologia de les Ciències del Comportament, Facultat de Psicologia, Divisió de \\ 7 Ciències de la Salut (IV), Universitat de Barcelona, Passeig de la Vall d'Hebron, 171, 08035 \\ 8 Barcelona, Spain
}

\begin{abstract}
9 Abstract. Many studies have examined the factors that influence academic performance in 10 primary and secondary education as well as at university, with the purpose of enhancing 11 learning at these stages and reducing drop-out rates. It is within this research framework 12 that we want to emphasise the deficient performance of students enrolled on the statistics 13 course in the Faculty of Psychology at the University of Barcelona. Consequently, this paper 14 attempts to determine the factors that affect student performance in this subject by under15 taking an analysis of a structural equation model and determining its stability over time. 16 In order to accomplish our objective, we worked with two samples of students enrolled sta17 tistics classes. The first group comprised 211 students enrolled in the academic year 200018 2001, while the second comprised 287 students enrolled in the academic year 2001-2002. By 19 administering a questionnaire, we obtained information concerning such variables as demo20 graphic data, previous academic record, information related to the subject and the degree of 21 satisfaction with it, and the final mark obtained by the students in the subject. The param22 eters for each group of students were estimated separately and the goodness of fit of the 23 proposed structural model was assessed. The data analysis showed a good fit with both 24 data bases, but the set of estimated parameters differed in the two academic years under 25 consideration.
\end{abstract}

26 Key words: academic performance, statistics, structural models.

\section{1. Introduction}

28 The difficulties encountered by psychology undergraduates in learning the 29 contents of the subject of statistics are well known in psychology facul30 ties, and among the lecturers of this subject, throughout Spain. We believe

\footnotetext{
* Author for correspondence: Joan Guàrdia, Dept. de Metodologia de les Ciències del Comportament, Facultat de Psicologia, Divisió de Ciències de la Salut (IV), Universitat de Barcelona, Passeig de la Vall d'Hebron, 171, 08035 Barcelona, Spain, E-mail: jguardia @ub.edu
} 
these difficulties are caused by two main factors: first, the great differences encountered in the academic backgrounds of the new undergraduates on being admitted to the university, especially in recent years following the introduction of the educational reform act known as the Ley de Ordenación General del Sistema Educativo (LOGSE) and, second, and directly linked to this first factor, the fact that first-year undergraduates do not expect to find a subject based on mathematics on the psychology curriculum. Indeed, given these circumstances, it might be the case that not all the first-year students in the Faculties of Psychology possess the academic pre-requisites to cope successfully with the demands of the subject of statistics, which in the case of the Psychology faculty of the University of Barcelona is entitled Anàlisi de Dades en Psicologia (Data Analysis in Psychology).

Various attempts have been made to improve the performance of the students enrolled on this subject. Since the academic year 1999-2000, the faculty has introduced an optional subject to raise the level of those whose mathematics skills are insufficient, known as Fonaments Matemàtics (Basic Mathematics), specifically designed for those students with little training in mathematics in their pre-university courses in which the presence of mathematics is negligible (Arts and Humanities, for example). Furthermore, and forming part of the framework of pedagogic research which we seek to promote, a number of empirical studies have been undertaken in an attempt to determine the factors influencing student performance in this subject (Barrios et al., 2000; Guàrdia et al., 2002; Peró et al., 2002). This paper can be considered as a continuation of these previous studies and, at the same time, as an attempt to provide a summary of contributions reporting empirical evidence over the last few years concerning the factors influencing academic performance in statistics.

The first question to undertake, and a vital element in any discussion of the academic performance of students at whatever stage of their education, is just how we might define academic performance and, similarly, determine which indicators can be used in its measurement (Gabinet d'Orientació Universitària, 2000a, b). In general, the question of academic performance has been posed as a global question and has usually been the object of very broad, general proposals as well as of theoretical models concerning its conceptual definition (Loeb, 1994; Liljander, 1998). However, the aim we set here has meant that we must centre our analysis on aspects linked more specifically with the characteristics of the subject of statistics. Various studies have been undertaken in primary, secondary and university education that have examined performance in subjects such as statistics or those of an analytical-methodological nature, either at a theoretical or empirical level. Examples of theoretical studies are those of Hunt and Tyrrell (2000) and Hodgson and Burke (2000). Hunt and Tyrrell (2000) highlight the significance of the introduction of new technologies, 
in particular the Internet, in the teaching of statistics. On the other hand, Hodgson and Burke (2000) argue in favour of the introduction of simulations accompanied by a good introduction to the subject matter, as well as the monitoring and appraisal of the work undertaken by the students as essential elements in the best practice of the teaching of statistics and the evaluation of academic performance.

The studies that adopt an eminently practical approach are those that examine the importance of variables related to the role of motivation, personality and psychosocial factors (Castejón et al., 1996; Garrido and Rojo, 1996; Pérez-Sánchez and Castejón, 1996; Roces et al., 1997; García and Fumero, 1998) in the performance of students. Further studies identify a wide range of factors related to academic performance in the study of analytical subjects among university students, including previous academic record, in other words, the mark awarded in the University entrance examinations, performance in the pre-university course (bachillerato in our case) and the branch of studies selected during this pre-university course (Alvarado and García, 1999-2000 García et al., 2000), as well as attendance at and participation in the classroom (Alvarado and García, 19992000; García et al., 2000; Huberty, 2000). Finally, findings such as those made by Gal and Ginsburg (1994) and Garfield (1994) highlight the need to take into consideration students' attitudes towards and beliefs concerning statistics and Smith (1998), Boyle (1999) and Gardner and Hudson (1999) comment on the utility of students undertaking practical tasks in which they have to apply various statistical techniques while learning statistics. It is within this context that we should situate our traditional approach and this present study.

It was Barrios et al. (2000) who established the path taken by students in order to enter university (COU versus LOGSE), the branch of studies selected in the bachillerato (equivalent to the high school diploma, that is, option $\mathrm{A} / \mathrm{B}$ - science or health sciences - versus option $\mathrm{C} / \mathrm{D}$ - social sciences or humanities) and the mark awarded in the university entrance examinations (PAAU) as the predictive variables based on the fit of a stepwise optimal linear regression model. The results showed that each had a slightly significant effect in predicting academic performance, measured by the mark awarded in the final assessment of the subject.

In previous studies Guàrdia et al. (2002) and Peró et al. (2002), we proposed various modifications in the use of these variables, and extended some of the measures that we considered to be linked to performance in the subject of statistics. The main change was in the development of a Likert-style satisfaction scale (assessed on a scale from 0 to 7) concerning aspects related to the subject. This was based on the hypothesis that a student's satisfaction might be directly linked to his or her performance. This scale was generated ad hoc for each study, given the different teaching 
117 programmes adopted in each academic year for the subject. In the first study

118 (Guàrdia et al., 2002), the scale comprised 16 items, while in the second

119 (Peró et al., 2002) 14 items were included, as the two items that referred to

120 the teachers of the practical sessions were eliminated since in that academic

121 year (2001-2002) the syllabus did not distinguish between the teachers of the

122 practical sessions and the teachers of theory. The databases for both years

123 were examined, among other analytical processes, using factorial analysis in

124 order to study the underlying structure of both scales of satisfaction. In the

125 data for the academic year 2000-2001 (Guàrdia et al., 2002), the 16 items

126 were grouped in five sets of factors (satisfaction with the teachers, knowl-

127 edge acquired, the teaching methods used in the subject, the teachers of the

128 practical sessions and the teaching conditions) which accounted for $64.7 \%$

129 of the variability. For the data for the academic year 2001-2002, the facto-

130 rial analysis included three factors (satisfaction with the teachers, importance

131 attached to the subject and the organisation of the subject) which accounted

132 for $55.15 \%$ of the overall variability.

133 The bivariable contrasts between academic performance and the factors

134 obtained in the factorial analysis and other variables collected in the ques-

135 tionnaire were not statistically significant in the 2000-2001 study, while

136 in the 2001-2002 study a statistically significant relation was only found

137 with the branch of studies selected in the bachillerato (technical science

138 and/or biology resulting in a better performance than humanities and/or

139 social sciences). Furthermore, in both samples a study of the goodness

140 of fit of a system of structural equations was undertaken, in order to

141 determine which structure and factors influenced the academic performance

142 of students enrolled in the subject of Data Analysis in Psychology. The

143 overall results showed the effect on the two models of the following fac-

144 tors: First, the effects of the academic record prior to initiating univer-

145 sity studies (the branch of studies selected in the bachillerato, the mark of

146 the university entrance examinations, the fact of having studied statistics

147 before or not, choosing of psychology as the first option when selecting

148 which university degree to take and, finally, whether or not the student was

149 repeating the subject); second, the estimated mark (the final mark that the

150 student expects to obtain in the subject) and, finally, the factor of satis-

151 faction expressed by the students (as regards the teachers, the information

152 taught, the teaching methods used in the subject, the teachers of the prac-

153 tical sessions and the conditions of study for the academic year 2000-2001

154 and similarly for the academic year 2001-2002). In both cases the good-

155 ness of fit of the model was adequate. In addition, the three latent fac-

156 tors that were defined were statistically significant, although their relative

157 weighting varied in the two studies. In the first (2000-2001), the latent var-

158 iable "previous academic record" had greater importance, followed by the

159 "estimate of the final mark" and finally the "degree of satisfaction", while 
160 in the second (2001-2002), the "degree of satisfaction" obtained a higher

161 importance, followed by "previous academic record" and finally the "esti-

162 mate of the final mark".

163 The results of these studies show the well-known effect of dispersion

164 that is typical in studies of academic performance. It is difficult to adopt

165 a definitive position for a set of results since none is conclusive. However,

166 the results for the group of students in the academic year 2001-2002 (Peró

167 et al., 2002) provide a simpler factorial solution and, consequently, one

168 that is more parsimonious in detecting factors that have an effect on aca-

169 demic performance in this subject. The structural models analysed form

170 the two factorial solutions and, therefore, analysed in the two populations

171 also show the dispersion discussed above (Guàrdia et al., 2002; Peró et al.,

172 2002).

173 In this study we attempt to analyse the common information from the

174 studies undertaken by Guàrdia et al. (2002) and Peró et al. (2002), which

175 basically requires us to reconsider the factorial analysis undertaken in the

176 first study (Guàrdia et al., 2002) and consequently the structural model.

177 Once the structural model has been defined (identical in both years), we

178 can then proceed to the study of its goodness of fit, as well as to a com-

179 parison of the indices of fit of the two academic years, in order to eval-

180 uate the stability of the proposed structure. The structural model that we

181 propose studying for the two academic years is that analysed for the 2001-

1822002 data (Peró et al., 2002), and which is shown in Figure 1.

\section{2. Method}

\section{2.1. SUBJECTS}

185 We studied two samples of students enrolled in the subject Data Analy186 sis in Psychology. The first sample comprised 211 students enrolled in the 187 course in the academic year 2000-2001, while the second sample comprised 188287 students enrolled on the course in the academic year 2001-2002. The 189 choice of students that made up the two samples was determined entirely 190 on the basis of those students that attended the class when the question191 naire was administered, and which in addition made the final examination 192 (accidental sampling).

193 Of the students enrolled in 2000-2001, $18.7 \%$ were male and $81.3 \%$ 194 female, with an average age of 19.7 years and a standard deviation of 1953.5 years. Among the students enrolled in 2001-2002, 14\% were male and $19686 \%$ female, with an average age of 19.48 years and a typical deviation of 1973.02 years. Given these data, we can conclude that the distribution of both 198 variables was very similar in the two groups studied. 


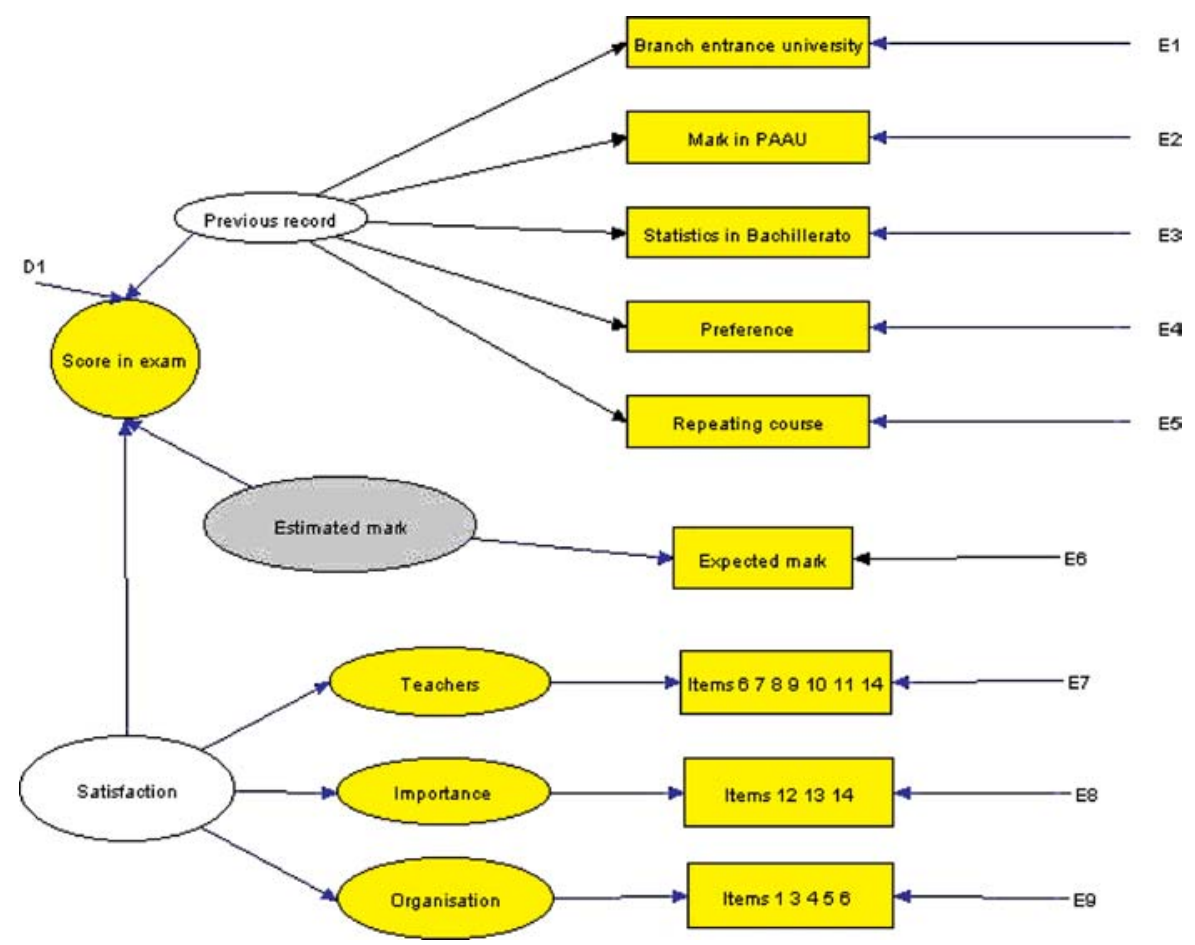

Figure 1. Diagram illustrating the proposed structural model.

\subsection{MATERIAL}

200 The material used comprised the subject examination and an ad hoc ques201 tionnaire based on an extension of that used by Barrios et al. (2000). The 202 questionnaire aimed to gather information that might have an influence on 203 the students' academic performance in the subject of statistics. The ques204 tionnaire contained the following information:

205 - Demographic variables: gender and age.

206 - Previous computer knowledge, how this had been acquired, if they have a computer at home and if they have an internet connection at home.

- Use of the electronic dossiers on the UB Web produced for the studying of the subject (syllabus, bibliography, statistical equation summary and solution of practical problems).

- Whether the student had taken previous courses in statistics, either the option offered as part of the studies in LOGSE or as a part of other courses.

214 - Whether the student had taken the subject of Basic Mathematics. A course designed to raise the level of those students encountering difficulties in analytical-methodological subjects in Psychology. 
- Survey of satisfaction comprising 16 items on the questionnaire administered to students in the academic year 2000-2001 and by 14 items on that administered to students in the academic year 2001-2002. All the items were presented on a Likert-style scale where students responses range from strongly disagree (1) to strongly agree (7). The 14 items on the questionnaire administered in the academic year 2001-2002 can be grouped in the following four areas:

- Aspects related to the subject, comprising the following three items:

- the knowledge acquired is important for the rest of the degree (question 12)

- the knowledge acquired is important for one's professional career (question 13)

- overall, the subject deserves a favourable evaluation (question 14)

- Aspects related to the teachers, comprising the following six items:

- the teacher seems to master all aspects of the subject (question 6)

- the teacher is able to motivate the class (question 7)

- the teacher is able to awaken the interest of the students for the subject (question 8)

- the teacher makes good use of the examples chosen (question 9)

- the teacher has been willing at all times to deal with students' queries (question 10)

- the teacher creates a friendly atmosphere which encourages participation (question 11)

- Aspects related to the methodology adopted, comprising the following four items:

- the time dedicated to each subject within the course is sufficient (question 2)

- the system of evaluation used in the subject is understood and meets the requirements of the syllabus (question 3)

- the dossier of practical problems is useful for the student (question 4)

- the recommended reading list is useful for understanding the subject (question 5)

- Aspects related to the conditions in the classroom, comprising one item, including the lighting, heating and ventilation of the classrooms are sufficient (question 1)

The two items that were eliminated for the academic year 2001-2002 referred to the mastery of the subject demonstrated by the teacher of the practical sessions and to the degree of coordination between this teacher and the teacher of theory, because the course structure differed in the second year. 
- The students previous academic record. Specifically, the mark awarded in the university entrance examination (PAAU) and the branch of studies selected during the pre-university courses (sciences or health sciences vs. social sciences or humanities).

- Data related to the subject studied. In other words, whether the student attended the class regularly, whether or not they were repeating the course, the mark they expected to obtain and whether the degree of psychology had been their first choice.

\subsection{PROCEDURE}

The questionnaire was administered to the students enrolled in the academic year 2000-2001 during the first fortnight of December 2000, while for the students enrolled in the academic year 2001-2002 it was administered between 17 and 21 December 2001. In both cases, the instructions given to the students emphasised the importance of answering the questionnaire sincerely given that its aim was to determine the factors influencing performance in the subject Data Analysis in Psychology and that it was very important to know the students' national identity number so that the results of the questionnaire could be compared with the final mark obtained in the subject. Students were reassured that the data gathered would be kept confidential and that the information would only be used for the purposes of the study.

The date of examination was on the 16 January 2001 in the case of the first sample and on 16 January 2002 in the case of the second. The score obtained in the examination, together with that awarded for the assignment undertaken as part of the course, gave the final mark for the subject out of 10 , where 5 was considered the cut-off point between a pass and a fail.

The data analysis undertaken consisted of the fit of the structural model proposed in the introduction using the EQS program (version 5.1).

\section{Results}

As discussed above, we estimated the parameters and undertook a study of the goodness of fit of the structural model proposed in the introduction (Figure 1). In this figure, it can be seen that the mark obtained in this subject is determined by the student's previous academic record, the mark expected and their degree of satisfaction. The previous academic record factor is defined by the observable variables of the branch of studies taken by students in order to enter university, the mark obtained in the university entrance examination (PAAU), whether or not the student had studied statistics before, whether or not the student was repeating this subject of data analysis and whether or not psychology had been the student's first 
Table I. Factor structure of the satisfaction scale based on the data obtained in the academic year 2001-2002.

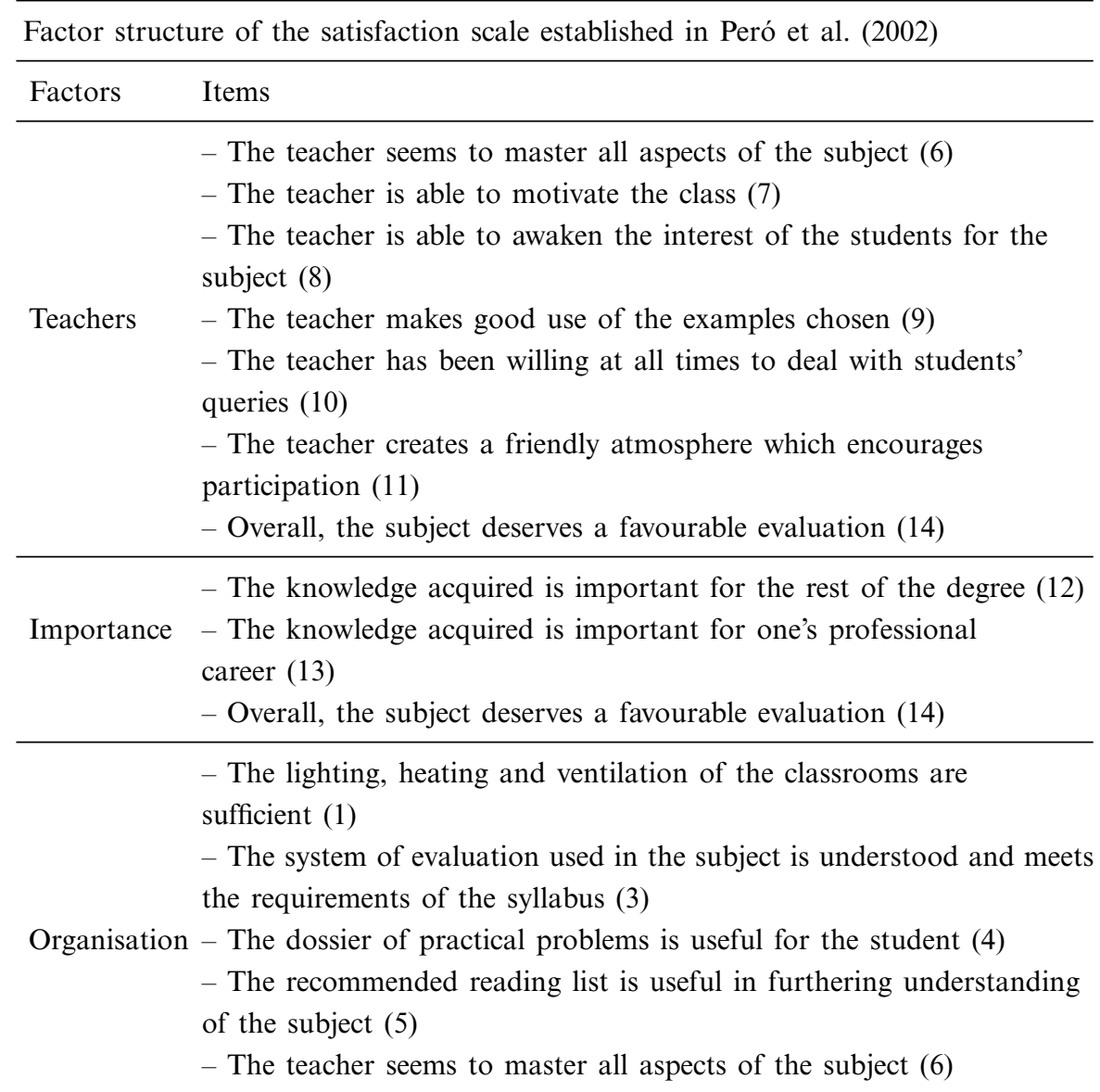

297 choice of study at university. The factor of "mark expected" is defined by 298 the observable variable mark expected in the subject (fail, pass, good, excel299 lent and pass with distinction), while the factor of satisfaction is defined by 300 three factors, namely, the teachers, the importance of the subject and the 301 organisation of the subject, obtained by factor analysis based on the items 302 on the satisfaction scale contained on the questionnaire administered in the 303 academic year 2001-2002 (Peró et al., 2002). The resulting factor structure 304 is shown in Table I.

305 The method of parameter estimation used in the two structural models 306 studied was the elliptical robust least square method (ERLS) given the 307 existence of categorical variables among the observable variables (Lee and 308 Poon, 1994). Table II shows the indices of fit of the model analysed for the 
Table II. Indices of fit for the model studied in the two academic years 2000-2001 and 2001-2002.

\begin{tabular}{ccc}
\hline Indices of fit & Academic year 2000-2001 & Academic year 2001-2002 \\
\hline BBNFI & 0.801 & 0.978 \\
BBNNFI & 0.911 & 0.966 \\
SRMR & 0.002 & 0.008 \\
$\chi^{2}=$ & $35.392 ; \mathrm{df}=29 ; p=0.15875$ & $55.1278 ; \mathrm{df}=29 ; p=0.11$ \\
\hline
\end{tabular}

Where BBNFI is the Bentler-Bonett normed fit index, BBNNFI is the Bentler-Bonett non-normed fit index, SRMR is the standardised root mean square residual and $\chi^{2}$ is the chi-square index of fit.

student samples studied. In both cases, it should be noted that the fit of the model is good, with a goodness of fit of $\chi^{2}=35.39(p=0.159)$ for the data corresponding to the academic year $2000-2001$ and $\chi^{2}=55.128(p=0.11)$ for the data corresponding to the academic year 2001-2002, and that the SRMR value (standardised root mean square residual) is 0.002 and 0.008 , respectively, which indicates only a slight error and, consequently, a good data fit with the model in the two samples analysed.

Table III shows the standardised estimate of the parameters for the two groups under study. In the two analyses conducted, the parameters corresponding to the three factors that predict the mark obtained in the subject were statistically significant, with the exception of $\gamma_{13}$ (satisfaction - examination score) for the data corresponding to the academic year 2000-2001. It should be noted that the relationship between these three latent variables and academic performance differs in the two analyses conducted. The first point to highlight is the fact that in the data corresponding to the academic year 2000-2001 the parameter estimate value is markedly lower than that obtained for the data corresponding to the academic year 2001-2002, the highest value in the estimate for the academic year 2000-2001 is 0.948 corresponding to the factor of previous academic record, while the parameter with the lowest value for the 2001-2002 data is 3.29 corresponding to the factor of expected mark in the subject. A second aspect to highlight is the fact that although the three factors have an influence on the final mark obtained by the students in the subject, their importance is not the same in the two groups analysed; thus for the data corresponding to the academic year 2000-2001 the factor with the greatest weight in the prediction of the mark is that of the previous academic record, followed by the mark expected in the subject and finally by the satisfaction with the various aspects related to the teaching of the subject. As for the results of the model for the data corresponding to the academic year 2001-2002, the factor that has the greatest weight in the prediction of the mark obtained by 
Table III. Estimate of the model's standardised parameters based on the ERLS method for the data corresponding to the academic years 2000-2001 and 2001-2002.

\begin{tabular}{ccc}
\hline Estimates & Academic year 2000-2001 & Academic year 2001-2002 \\
\hline$\gamma_{11}$ & $0.948^{*}$ & $4.07 *$ \\
$\gamma_{12}$ & $0.313^{*}$ & $3.29 *$ \\
$\gamma_{13}$ & $0.053^{* *}$ & $5.12 *$ \\
$\lambda_{43}$ & $0.421 *$ & $0.842^{*}$ \\
$\lambda_{53}$ & $0.759^{*}$ & $0.718^{*}$ \\
$\lambda_{63}$ & $0.377^{*}$ & $0.601 *$ \\
\hline
\end{tabular}

$* p<0.05 ; * *$ Non-significant.

$\gamma_{11}$ : previous record - score in exam; $\gamma_{12}$ : estimate mark - score in exam; $\gamma_{13}$ : satisfaction - score in exam, $\lambda_{43}$ : satisfaction with teachers satisfaction; $\lambda_{53}$ : importance attached to the subject - satisfaction; and $\lambda_{63}$ : organisation of the subject - satisfaction.

339 the students is satisfaction with the various aspects related with the teach340 ing of the subject, followed by the previous academic record and finally the 341 mark expected in the subject.

342 Finally, Table III also shows the standardised estimate of the parame343 ters corresponding to the latent factors that account for the factor of satis344 faction, that is, in relation to the teachers, the importance attached to the 345 subject and the organisation of the subject. Here once again there was a 346 repetition of the phenomenon described earlier, the estimated value of the 347 parameters is notably lower in the case of the data corresponding to the 348 academic year 2000-2001 than for the data corresponding to the academic 349 year 2001-2002.

\section{4. Discussion}

351 The analysis of the proposed structural model shows satisfactory indices of 352 fit for the two data bases studied $\left(\chi^{2}=35.392 ; p=0.159\right.$ for the data cor353 responding to the academic year 2000-2001 and $\chi^{2}=55.128 ; p=0.11$ for 354 the data corresponding to the academic year 2001-2002). In fact, the values 355 of these indices are very similar, with the Bentler-Bonett normed fit index 356 showing the greatest discrepancy between the two analyses $(0.801$ for the 357 academic year 2000-2001 as opposed to 0.978 for the academic year 2001358 2002).

359 The three factors (previous academic record, estimate of the mark and 360 satisfaction) proposed here as predicting the final mark obtained in the 361 subject do have such an influence, as has already been demonstrated, albeit 
362 only in part, in earlier studies (Alvarado and García, 1999-2000; Alvarado 363 et al., 2000; Barrios et al., 2000; Guàrdia et al., 2002; Peró et al., 2001).

364 However, the importance of these three factors in predicting the mark is 365 not the same in the two databases. For the data corresponding to the aca366 demic year 2000-01, the most important factor is that of the previous aca367 demic record, followed by the mark expected in the subject and finally 368 by the satisfaction, which, moreover, is not statistically significant; indeed, 369 this is the same pattern as that found in the structural model analysed by 370 Guàrdia et al. (2002); by contrast, in the case of the data for the academic 371 year 2001-2002, the factor with the greatest weight in the prediction of the 372 mark obtained by the students is satisfaction, followed by the previous aca373 demic record and finally the mark expected. This result suggest that there 374 is no stability in the proposed structure. A further argument against the 375 stability of the structure is the marked difference in the estimate of the 376 standardised parameters for the two data bases studied, with the estimated 377 values for the data corresponding to the academic year 2001-2002 being 378 much higher than those estimated for the academic year 2000-2001.

The results obtained show the well known dispersion effect in the study of academic performance. Despite the good fit of the data with the model for the two samples studied here, we have to conclude that there is no stability in the proposed structure, and that possibly the factors that influence the students' academic performance in the subject of Data Analysis in Psychology should be sought adopting a different approach.

Here again the difficulty in predicting a person's academic performance accurately is patent. It might be the case that there exists a very large group of factors that are not readily operationalised, but which influence the outcome. Furthermore, the difficulties faced in the statistical modelling of a phenomenon such as academic performance should be considered, particularly where individual differences and those that are generated between the times of measurement have a marked influence on the process. Prior information will not always be a good predictor of the subsequent performance of all people, and this can be attributed to varying degrees of motivation in a person's academic studies. Students at university are assumed to be studying a subject that they have chosen and it is to be hoped that their motivation and interest for this subject will be greater than that shown during primary and secondary education, which would uphold a more dynamic conception of the educational process.

To conclude, taking into consideration the three latent factors that we studied in the structural model what seems to be needed are procedures 401 of direct intervention. Indeed, as regards the factor of previous academic 402 record, we believe that it is vital to strengthen subjects that might raise the 403 level of the students who have little training in maths, such as Basic Math404 ematics discussed in the introduction, in order to homogenise the prior 
mathematical knowledge needed to perform successfully in the subject of the Data Analysis in Psychology. If this occurs, it seems logical to think that the second factor, students' expectations, will be influenced by the degree of prior preparation. Thus the students, in line with their level of knowledge at the outset will express greater expectations concerning their own future performance in the subject.

It would be interesting to examine in more detail the effect on the degree of satisfaction expressed of recent developments in the quality of teaching, including:

- The use of new technologies of information and communication:

- computer presentation of subject matter

- use of computer-based statistics programs

- e-mail correspondence with the tutor

- virtual presentation of exercises by the students

- evaluation system based on continuous tests.

Clearly these changes in the delivery of the subject will need to be analysed and studied, in the near future, in order to obtain sufficient evidence so that they might be adopted in the actual teaching setting.

\section{References}

Alvarado, J. M., \& García, M. V. (1999/2000). Incidencia de la asistencia a clase, del trabajo efectivo y de factores individuales sobre el rendimiento académico. In: A. M. López, J. L. López \& R. Moreno (eds.) Proceedings of the $V$ congreso de Metodología de las C.C. Humanas y Sociales, 23-26 September 1997, Sevilla, pp. 683-686.

Barrios, M., Cosculluela, A., Freixa, M., Guàrdia, J., Peró, M. \& Turbany, J. (2000). La transición entre el bachillerato y la asignatura de estadística en la facultad de Psicología de la Universidad de Barcelona. In: C. Loureiro, F. Oliveira \& L. Brunheira (eds.), Proceedings of the Encontro sobre Ensino e Aprendizagem da Estadistica, 3 - 4 February 2000, Lisboa, pp. 93-102.

Boyle, C. R. (1999). A problem-based learning approach to teaching biostatistics. Journal of Statistics Education, 7(1).

Castejón, J. L., Navas, L. \& Sampascual, G. (1996). Un modelo estructural del rendimiento académico en matemáticas en la educación secundaria. Revista de Psicología General y Aplicada, 49(1): 27-43.

Gabinet d'Orientació Universitària (2000a). Gabinet d'Orientació Universitària. Colecció Gabinet d'Orientació Universitària 1. Barcelona: Edicions Universitat de Barcelona.

Gabinet d'Orientació Universitària (2000b). Actes del Congrés d'Orientació Universitària. Colecció Gabinet d'Orientació Universitària 3. Barcelona: Edicions Universitat de Barcelona.

Gal, I. \& Ginsburg, L. (1994). The role of beliefs and attitudes in learning statistics: towards an assessment framework. Journal of Statistics Education 2(2).

García, L. \& Fumero, A. (1998). Personalidad y rendimiento académico en estudiantes universitarios: un estudio predictivo en tres cursos académicos. Análisis y Modificación de Conducta 24(93): 65-77. 
García, M. V., Alvarado, J. M., \& Jiménez, A. (2000). La predicción del rendimiento académico: regresión lineal versus regresión logística. Psicothema, 12 (Suppl. 2): 248-252. Gardner, P., \& Hudson, I. (1999). Universtiy students' ability to apply statistical procedures. Journal of Statistics Education, 7(1).

Garfield, J. B. (1994). Beyond testing and grading: using assessment to improve student learning. Journal of Statistics Education, 2(1).

Garrido, I. \& Rojo, C. (1996). Motivación, cognición y rendimiento. Revista de Psicología General y Aplicada, 49(1): 5-12.

Guàrdia, J., Freixa, M., Turbany, J., Cosculluela, A., Peró, M., Barrios, M. \& Rifà, X. (2002). Estudio sobre los factores que inciden en el rendimiento académico en la asignatura análisis de datos en Psicología. Metodología de las Ciencias del Comportamiento, volumen especial: $78-80$.

Hodgson, T. \& Burke, M. (2000). On simulation and the teaching of statistics. Teaching Statistics, 22(3): 91-96.

Huberty, C. J. (2000). Assessment of student performance in statistics. Teaching Statistics, 22(2): $44-48$.

Hunt, N. \& Tyrrell, S. (2000). Learning statistics on the WEB - DISCUSS. Teaching Statistics, 22(3): 85-90.

Lee, L. \& Poon, C. (1994). Structural Equation Models. EQS Guide. California: University of Los Angeles Press.

Liljander, J. P. (1998). Gains and losses on academic transfer markets: dropping out and course-switching in Higher Education. British Journal of Sociology of Education 19(4): 479-495.

Loeb, L. S. (1994). Community career services: the past, present and future. Journal of Career Development, 21(2): 167-169.

Pérez-Sánchez, A. M. \& Castejón, J. L. (1996). Factores psicosociales en la predicción del rendimiento académico. Revista de Psicología de la Educación 19: 31-51.

Peró, M., Guàrdia, J., Freixa, M. \& Turbany, J. (2002). Evaluación de los factores que inciden en el rendimiento académico de los alumnos de la asignatura "Anàlisi de dades en Psicologia". Proceedings of the " $2{ }^{\circ}$ Congreso Internacional Docencia Universitaria e Innovación”. 1-3 July 2002, Tarragona.

Roces, C., González, M. C., \& Touron, J. (1997). Expectativas de aprendizaje y de rendimiento de los alumnos universitarios. Revista de Psicología de la Educación, 22: 99-123.

Smith, G. (1998). Learning statistics by doing statistics. Journal of Statistics Education 6(3). 